$\begin{array}{ll} & \text { Etnográfica } \\ \text { etnográfica } & \text { Revista do Centro em Rede de Investigação em }\end{array}$

Antropologia

vol. 15 (1) | 2011

Vol. $15(1)$

\title{
Filipe Verde, O Homem Livre: Mito, Moral e Carácter Numa Sociedade Ameríndia
}

\section{Frederico Delgado Rosa}

\section{OpenEdition}

\section{Journals}

\section{Edição electrónica}

URL: https://journals.openedition.org/etnografica/890

DOI: 10.4000/etnografica.890

ISSN: 2182-2891

\section{Editora}

Centro em Rede de Investigação em Antropologia

\section{Edição impressa}

Data de publição: 1 fevereiro 2011

Paginação: 201-203

ISSN: 0873-6561

\section{Refêrencia eletrónica}

Frederico Delgado Rosa, «Filipe Verde, O Homem Livre: Mito, Moral e Carácter Numa Sociedade

Ameríndia», Etnográfica [Online], vol. 15 (1) | 2011, posto online no dia 23 outubro 2011, consultado o

12 fevereiro 2022. URL: http://journals.openedition.org/etnografica/890 ; DOI: https://doi.org/10.4000/ etnografica.890

Etnográfica is licensed under a Creative Commons Attribution-NonCommercial 4.0 International License. 
Filipe Verde

\section{O HOMEM LIVRE: MITO, MORAL E CARÁCTER NUMA SOCIEDADE AMERÍNDIA}

Coimbra, Angelus Novus, 2008, 224 páginas.

É preciso audácia para dizer algo de novo, no século XXI, sobre a sociedade e a cosmologia tradicionais dos Bororo, um dos povos mais revisitados de sempre, tanto etnográfica como teoricamente. Filipe Verde vai mais longe, pois que se propõe através deles "aprender coisas significativas sobre nós" (p. 12), num implícito manifesto de devolução à antropologia da sua ambição de ser ciência do Homem. Numa linguagem desprovida de jargões, estamos perante um livro que põe em diálogo mundivisões distantes e que abala, com erudição rara, alicerces antigos da perceção que o Ocidente tem de si próprio e do "outro". Conhecedor exaustivo da literatura sobre os Bororo, o autor foi ao encontro dos mesmos em 1998, numa viagem com o seu quê de pungente, abreviada pelo vislumbre de que chegara "tarde demais" (p. 93). Decididamente, não era o estado dos índios no mundo de hoje que lhe interessava, mas a sua singularidade de outrora. O regresso ao arquivo etnográfico, na posição assumida de repensar as observações feitas por outros, não deixou contudo de o pôr em contacto com certos agentes de desintegração do universo tradicional Bororo, responsáveis em simultâneo por uma das mais colossais empresas de etnografia de salvação em contexto amazónico: os missionários salesianos. O proselitismo etnocêntrico destas figuras não as impediu de conhecer em profundidade os índios Bororo, ou não fosse a duração desse convívio, iniciado em 1895, incomparavelmente superior à de qualquer antropólogo. $\mathrm{O}$ autor reconhece que o seu próprio conhecimento é indissociável do legado desses homens, mas não se limita a render-lhes homenagem. Faz-lhes também uma crítica - que se encontra no âmago mesmo da obra. Os missionários foram os primeiros a negar sabedoria moral aos Bororo, uma sabedoria que até hoje não lhes tinha sido devolvida. Trata-se, convenhamos, de uma proeza antropológica, em diálogo com a filosofia e a história.

O índio, escreveu em 1919 o salesiano Antonio Colbacchini, primus inter pares dos missionários-etnógrafos, "é a imagem perfeita do homem inteiramente livre". Esta frase inspiradora do título do livro de Filipe Verde trazia associado, na origem, um juízo de valor sobre a ausência de coações morais e do benéfico sentimento de culpa que os convertidos ao cristianismo deveriam passar a experimentar no seu foro mais íntimo. Foi também Colbacchini, numa segunda monografia, o primeiro a divulgar um mito Bororo que se tornaria por sua vez um mito da antropologia: justamente o que Lévi-Strauss veio a utilizar em abertura das 
Mythologiques. Recorde-se rapidamente que conta a história de um rapaz que viola a mãe e é descoberto pelo pai, acabando por os matar aos dois. Recorde-se também que o mito de referência de Lévi-Strauss tem sido retomado como tal por outros antropólogos, enquanto puzzle hermenêutico da sociedade Bororo tradicional. E a verdade é que tem perdurado a ideia da ambiguidade moral dessa história que, contra as expetativas de reforço da conduta em sociedade, inopinadamente deixa impune o incestuoso assassino. Os esforços de articulação entre a narrativa mitológica e a convivência humana têm justamente pecado, argumenta Filipe Verde, pelo recurso às noções de culpa, punição, responsabilidade e compensação, que radicam de modo inelutável na velha genealogia moral do Ocidente. O autor fala-nos então de um desencontro de já longa duração entre nós e os Bororo e luta por um ponto de vista que inverta a questão. Em sintonia, neste aspeto, com certas transformações epistemológicas da antropologia contemporânea, trata-se também de ultrapassar a tendência ou tentação de explicar o social pelo social, ou o cultural pelo cultural. Em vez de olhar nessa direção em busca de normas morais, não será tempo de explorar o potencial ético dos impulsos da bestialidade humana? Eis o que, segundo Filipe Verde, os Bororo fizeram à sua maneira, para desconcerto e incompreensão dos observadores ocidentais.

Seres peludos, negros e quentes, de olhos vermelhos e pés bifurcados, os espíritos bope eram a personificação hiperbólica de todos os apetites da vida orgânica, do alimentar ao sexual, nas suas sucessivas e violentas transformações. Ao mundo dos bope opunha-se, cosmologicamente falando, o dos aroe, espécies animais idealizadas numa dimensão imutável e transcendente, cristalizadora do património de nomes, adereços e cantos dos grupos Bororo. À primeira vista, a não anarquia da vida em sociedade pouco ou nada deveria aos bope - cujo exemplo totalmente predatório não era seguido pelos humanos e muito ou tudo deveria aos aroe. Mas por que razão, então, o conhecimento relativo a estes últimos era esotérico, influenciando somente a esfera ritual, enquanto a obsessiva interferência dos primeiros nos assuntos humanos era matéria corrente de conversa? A assimetria entre a conduta desregrada dos bope e a conduta regrada dos homens não basta, diz o autor, para camuflar a estreita relação entre uma e outra. Há algo de bope em cada homem. Com uma diferença, porém, significativa: enquanto esses espíritos tinham uma quantidade ilimitada de raka, de sangue, de élan vital que lhes permitia saciar os instintos em permanência e sem consequências, os humanos desgastavam-se até à morte na consumação dos desejos. Nasciam no mundo dos aroe e a ele voltavam, mas a duração e a qualidade da sua passagem pela terra eram determinadas pela gestão que cada qual fazia dos seus pontos em comum com os bope, o mesmo é dizer, dos seus impulsos. É neste ponto que o autor identifica no pensamento tradicional dos Bororo uma sabedoria moral que não passava pela punição social dos comportamentos excessivos - o que gerou a miragem missionária de que o índio era inteiramente livre -, mas sim por uma regulação individual dos instintos sexuais, alimentares e agonísticos. A haver punição, ela estava contida nos próprios atos de cada um. Em suma, não era a sociedade que normalizava os homens, mas sim os homens que, por contenção voluntária, normalizavam a sociedade, numa combinação feliz entre liberdade e ordem.

Segundo os critérios clássicos, não se trataria de uma ética, mas o livro defende justamente que se trata de uma filosofia moral em moldes radicalmente diferentes dos ocidentais, porquanto assentes numa escorreita aceitação das profundezas sombrias da natureza humana. Houve, é claro, 
no Ocidente, quem as aceitasse também, com grande destaque para Freud na obra em apreço. Os Bororo poderiam quase dialogar com ele, só que nem ele pôde fazer mais do que evidenciar a repressão das pulsões humanas pela moral culpabilizadora em que assentava a sua civilização - melhor dizendo, em que assentava a civilização, segundo o mito totémico que o próprio criou em 1913. E quando ouviu falar em certas regiões felizes da terra onde não havia coerção, Freud dificilmente pôde acreditar, conforme o atesta a citação de abertura do livro. Tudo somado, a sabedoria dos índios não tinha paralelo no universo dos seus observadores. E assim, para exprimir essa categoria nova, que se acrescenta ao próprio pensamento antropológico, Filipe Verde criou a fórmula "naturalismo ético": "Ao naturalismo junta-se o 'ético', na medida em que para os Bororo o conhecimento das leis da natureza, do determinismo que faz com que cada ato de realização do prazer seja compreendido como um passo em direção à morte, é o quadro por referência ao qual é compreendida, se não a necessidade, pelo menos o caráter conveniente da aceitação e autoimposição de uma limitação da busca de satisfação dos impulsos da natureza pelo qual se restringe o prazer em função de uma vontade de viver" (p. 205).

Esta leitura, no mínimo surpreendente, não fica fechada no contexto ameríndio e contribui para uma reapreciação da história e da própria existência humana. A encerrar o livro, dando mostras de um gabarito humanístico pouco frequente, o autor traz para o debate antropológico a reflexão crítica dos helenistas da atualidade sobre a moral grega - em particular Bernard Williams que vêm rejeitando a tese segundo a qual a noção de pessoa foi um produto idiossincrásico do Ocidente, na transição platónica e cristã da cultura da vergonha para a cultura da culpa. Defende-se hoje que o julgamento de si próprio existia na Grécia homérica independentemente da reprovação coletiva; não por imperativo categórico, mas por gestão da felicidade do sujeito. Tal como na Amazónia, tratava-se de uma sabedoria moral sem culpa e, ao mesmo tempo, de uma sabedoria individual. A menoridade ética que durante muito tempo foi atribuída aos Gregos arcaicos é no fundo equiparável à menoridade ética que os missionários - e os próprios antropólogos, enquanto herdeiros inconfessados da civilização da culpa atribuíram aos Bororo. $\mathrm{O}$ que os índios nos ensinam, diz Filipe Verde, é "algo de semelhante ao que, mais uma vez, os gregos nos mostraram mas nós não fomos tantas vezes historicamente capazes de assimilar" (p. 207): que o homem livre não é o homem sem moral, mas aquele cuja moral não é uma coisa em si mesma.

Dizer algo de novo sobre os Bororo do passado é, ipso facto, reivindicar para a antropologia uma lógica de não rotura com o seu objeto clássico. E quando o resultado é incontornável, como sucede com a obra de Filipe Verde, a comunidade antropológica é levada a refletir sobre a coabitação saudável (e pacífica) de sensibilidades dominantes e de sensibilidades marginais. No prefácio do seu livro, e procurando chegar a um público leigo mais vasto, o autor afirma que o mesmo "não tem por leitores ideais antropólogos" e que "procura falar o mínimo indispensável sobre Antropologia" (p. 12). Cabe-nos, entretanto, acolher com entusiasmo este precioso texto no seio da nossa disciplina, como um dos mais relevantes da produção antropológica portuguesa contemporânea.

Frederico Delgado Rosa FCSH-UNL 